Cadernos de Clio, Curitiba, v. 11, $n^{\circ} .2,2020$

\title{
A FICÇÃO AFROFUTURISTA NA EDUCAÇÃO DECOLONIAL BRASILEIRA
}

\section{AFROFUTURIST FICTION IN BRAZILIAN DECOLONIAL EDUCATION}

Nathaly de Moraes Dias ${ }^{1}$

Bigger, you're part of something way bigger [...]

Bigger than the picture they framed us to see

Black is King, 2020

Resumo: A corrente afrofuturista, desenvolvida no século $\mathrm{XX}$, ganha cada vez mais espaço no meio artístico e intelectual com afro-diaspóricos de diferentes lugares da África e América que procuram destacar suas experiências frente às instituições que tentam silenciá-los. Com este alcance, a corrente pode ser inserida em uma educação decolonial brasileira a partir da Lei $n^{0}$ 10.639/2003 que estabelece o ensino de História e Cultura Afro-brasileira colaborando para a inserção do negro na história política, econômica e social, mas também em sua história individualizada como sujeito afrodiaspórico, oferecendo pertencimento e perspectiva de um futuro melhor. Para isto proponho o uso de produções cinematográficas afrofuturistas para compreensão desse passado e continuidade de um futuro negro.

Palavras-chave: Afrofuturismo; Afrodiaspóricos; Educação decolonial.

Abstract: The Afro-Futurist trend, developed in the 20th century, is gaining more and more space in the artistic and intellectual environment with Afrodiasporians from different places in Africa and America who seek to highlight their experience in front of institutions that seek to silence

\footnotetext{
${ }^{1}$ Graduanda do $5^{\circ}$ período do curso de História (Licenciatura/Bacharelado) pela Universidade Federal do Paraná. Email para contato: nathydias227@outlook.com. Endereço para o Currículo Lattes: http://lattes.cnpq.br/3120440851279257.
} 
them. With this scope, the current can be inserted in a Brazilian decolonial education starting from Law $n^{\circ} 10.639$ / 2003 that establishes the teaching of Afro-Brazilian History and Culture collaborating for the insertion of black people in political, economic and social history but also in their history individualized as an afrodiasporic subject, offering belonging and perspective for a better future. To this end, I propose the use of Afro-Futuristic cinematographic productions to understand this past and continue for a black future.

Keywords: Afrofuturism; Afrodiaspora; Decolonial education.

\section{Introdução}

O movimento afrofuturista organiza-se de maneira coesa no decorrer da segunda metade do século XX, com produções afrocentradas que oferecem representatividade ao afro-diaspórico, visto que este encontra-se frustrado em um meio político, econômico e social que constantemente desfavorece a sua existência com silenciamento e embranquecimento. $\mathrm{O}$ movimento é orquestrado para oferecer possibilidade de um futuro satisfatório para a pessoa negra, referenciando um passado que é interpretado de maneira positiva para além de afirmações construídas no seio do colonialismo e Imperialismo.

Desta forma, o desenvolvimento da afrocentricidade é emergente para que o afro-diaspórico seja capaz de moldar e externar suas experiências como tal, pois, segundo Ama Mazama, a idéia afrocêntrica desenvolve-se no sentido

de que nós africanos [e afro-diaspóricos] devemos operar como agentes autoconscientes, não mais satisfeitos em ser definidos e manipulados de fora. Cada vez mais controlamos nosso destino por meio de uma autodefinição positiva e 
assertiva. Os critérios dessa autodefinição devem ser extraídos da cultura africana (MAZAMA, 2019: 111).

Por conseguinte, com o intuito de projetar um futuro próspero ao afro-diaspórico, a corrente afrofuturista desenvolve-se concomitantemente ao movimento Pan-africanista, consolidando-se apenas no final do século XX, e pode ser definida a partir da afirmativa de Fábio Kabral enquanto uma "mescla entre mitologias e tradições africanas com narrativas de fantasia e ficção científica, com o necessário protagonismo de personagens e autores negras e negros" (KABRAL, 2019: 106). Em sua obra O Caçador Cibernético da Rua 13, apresenta um rico aparato semântico no intuito de "recriar o passado de valores, espiritualidade e tecnologia africanos por meio de narrativas ficcionais que projetam um futuro no qual o mundo iorubá prevaleceu" e consegue destacar e articular a experiência de uma pessoa negra projetando seu futuro em um meio tecnológico (KABRAL, 2019) que não necessariamente lhe explora sistematicamente. Concluo ainda que a inserção dos afro-diaspóricos nas ficções científicas absorve as experiências desta população e os aloca como agentes contribuintes da história econômica, política e cultural do meio em que vivem.

No Brasil, por muito tempo, elegeu-se "heróis nacionais" como principais figuras no enredo histórico do País, deixando de lado a contribuição de outros grupos que não aquele reconhecidamente branco-europeu. Consequentemente, o ensino da História reforçou as ideologias raciais colaborando para o não-pertencimento da população negra, tendo em vista o embranquecimento epistêmico e cultural. Todavia, 
no intuito de reconhecer a "contribuição do povo negro nas áreas social, econômica e política pertinentes à História do Brasil" (BRASIL, 2003), a Lei $\mathrm{n}^{\mathrm{o}}$ 10.639/2003 define a obrigatoriedade do ensino de História e Cultura Afro-Brasileira. Junto a isto e observando a possibilidade de uma educação decolonial, aqui compreendida como a aprendizagem que parte das experiências coloniais para expor visões de mundo diferentes daquelas oriundas da episteme europeia-ocidental e que visa a transformação de práticas e estruturas que se adequem às realidade em específico de africanos e afro-diaspóricos, como afirmam Catherine Walsh e Fernando Jorge Pina Tavares, proponho o uso de produções cinematográficas com enredos ficticios, futuristas e afrocentrados que entram no imaginário e apresentam novas formas de interpretação de um passado negro que não remeta apenas à experiência da escravidão.

Por isso, procuro neste trabalho apresentar um breve desenvolvimento da corrente afrofuturista inserido em um contexto de produções afrocentradas concomitante ao advento da própria ficção científica. Tento elucidar, a partir de alguns exemplos, o impacto destas produções em uma maior compreensão das experiências dos afro-diaspóricos. E, pontuando a emergência da Lei $n^{0} 10.639 / 2003$ para uma educação decolonial no contexto brasileiro, exemplifico a possibilidade de trabalhar com filmes afrofuturistas: Black is King, Preto Sai, Branco Fica e o curta Oyá: A Ascensão do Orixá para possibilitar uma educação antirracista que colabore para a mudança no imaginário que o afro-diaspórico tem de si, bem como daquele que o observa. 


\section{Afrocentricidade e Afrofuturismo}

Os séculos XIX e XX presenciaram o desenvolvimento da intelectualidade afrocentrada a partir do diálogo entre os africanos, em África, e afro-diaspóricos presentes na América. O termo afrocentricidade foi cunhado na década de 1980 por Molefi Asante (FINCH; NASCIMENTO, 2019), entretanto, na época, já apresentava grande contingente de produções. Seu desenvolvimento foi orquestrado como uma atitude de resistência à supremacia branca atrávés de produções literárias, rituais religiosos e movimentos sociais (abolicionistas) nos quais as populações negras agiam para definir-se e produzir um referencial para e por si mesmas (MAZAMA, op cit). Ainda que não organizados de forma coesa, ligando-se um ao outro, temos os romances de Maria Firmina dos Reis, considerada a primeira romancista brasileira, e os movimentos intelectuais e sociais do Haiti, que infligiram medo e esperança por representarem o estopim de movimentos que levaram ao abandono do sistema escravista - presenciado por toda a América no decorrer do século XIX e finalizado, com a abolição no Brasil, em 1888.

Com o advento da segunda corrente do Pan-Africanismo na metade do século XX, e sua fase marcada pela modernidade negra com produções artísticas afro-centradas, o movimento ganha força oferecendo uma unidade negra na história contra preceitos imperialistas e ramifica-se para diversas vertentes. A música é bem representada pelos jazz e ganha destaque com Sun Ra. A emergência de uma investigação melhor interpretada do passado 
negro pode ser exemplificada no trabalho de Cheik Anta Diop, onde o historiador trabalha a idéia de uma "origem africana da civilização" e afirma que "as nossas investigações nos convenceram de que o Ocidente não tem sido calmo o suficiente e objetivo o suficiente para nos ensinar corretamente a nossa história sem falsificações grosseiras" (DIOP, 1974: 15, tradução livre). No ramo artístico, livros e performances vão se desenvolvendo, com os destacados Ralph Ellison e Octavia Butler. Algumas destas produções são caracterizadas com o que Mark Dery denomina afrofuturismo. Em 1993, o autor americano entrevista escritores afro-americanos em seu artigo Back to the future: Interviews with Samuel R. Delany, Greg Tate and Tricia Rose, em que questiona a falta de pessoas negras na ficção científica.

A corrente afrofuturista pode ser entendida como um movimento estético-político de autoconhecimento das populações africanas e afro-diaspóricas que possibilita sua continuidade para o futuro frente ao genocídio e encarceramento epistêmico (SOUZA; ASSIS, 2019). A viagem pelo oceano Atlântico, a "porta do não retorno", até a América escravocrata produziu a destruição simbólica e material dos africanos com o seu passado, favorecendo o estranhamento e o não pertencimento com a terra nova. A partir disso, o movimento estrutura-se para fundamentar uma nova identidade direcionada ao futuro, a partir do passado africano, suprindo a ausência deste que ainda une ciência e tecnologia.

Edson Rangel afirma que o filme Space is the Place, de Sun Ra, pode ser compreendido a partir desta perspectiva de viagem incerta, unindo 
a estética futurista à mitologia egípcia (RANGEL, 2016). Sun Ra acredita que pessoas negras conseguem sobreviver apenas em sua terra natal, da qual foram tiradas e enviadas à uma terra estranha através das naves (navios), viajando pelo espaço (Atlântico) e estudados como aliens (ciência moderna). Assim, fugindo de uma terra oprimida, parte para um novo planeta levando consigo diversas pessoas negras, onde poderá oferecer um futuro melhor para aqueles habitantes.

Ainda que, de início, a ficção científica denote escassez quanto a uma efetiva representatividade negra, o que torna válido o questionamento de Dery, pessoas negras estavam produzindo o que viria a ser chamado de "afrofuturista" desde o final do século XIX, podendo-se afirmar que estas produções não alcançaram o mainstream apenas porque foram barradas pelo embranquecimento cultural. Embora sua análise privilegie os Estados Unidos, Lysa Yaszek oferece um panorama do que afirma ser as 3 fases do afrofuturismo (ibid.: 136). O afrofuturismo americano compreende os anos de 1850 a 1960 e é majoritariamente literário, com destaque para Sutton E. Griggs, com seu Imperium in Imperio (1899). Em sua segunda fase, o movimento caminha ao lado de movimentos sociais da década de 1960 e se expande para fora da América do Norte, ao passo que, já na terceira fase, com o auxílio de Octavia Butler, a "Grande Dama da Ficção Científica", avança em direção à amplitude global, compreendida a partir de 1980.

Neste contexto de finais do século XX, o advento da cultura pop, que facilita a imposição de valores, culturas e instituições para a organização da nova ordem mundial euro-americana, ligada a uma lógica de mercado 
neo-liberal, prevê possibilidades econômicas e tecnocientíficas que visam suprir os interesses de grupos econômicos que aspiram produzir este futuro em decorrência da condenação de parcelas inferiorizadas da sociedade (ALBUQUERQUE, 2015). Realizando uma pesquisa na plataforma Google “filmes de ficção cientifica anos 70, 80 e 90" deparamo-nos com filmes como De Volta Para o Futuro (1985), Jurassic Park (1993) e Robocop (1987): nenhum deles apresenta um personagem negro que tenha destaque no enredo. Com um alcance relativamente maior, ainda que remete a alguns anos, a série de desenho animado Os Jetsons (1962) apresenta a mudança no cotidiano de uma família branca de classe média mediante o advento da tecnologia em um nível utópico. O que chama a atenção é novamente a falta de personagens negros no enredo e merece destaque o papel da empregada, geralmente ocupado por mulheres negras, mas que neste caso é representado por um robô. Em última análise, o advento do afrofuturismo apresenta ainda a necessidade do protagonismo negro para além de uma lógica "eurofuturista”, a qual o afro-diaspórico não está inserido.

Por fim, cabe adicionar que, contrária ao futurismo convencional, o afrofuturismo maneja mitos e lendas de matrizes africanas, como simbologia e metafísica, diferente do Ocidente que apresenta história e conflitos (KABRAL, 2019). Fábio Kabral, principal precursor afrofuturista brasileiro, entende a corrente como uma maneira de "recriar o passado, transformar o presente e projetar um novo futuro", com a utilização da mitologia africana, e acompanha Clyde Ford, que afirma que "quando enfrentamos um trauma, individual ou coletivamente, as lendas e os mitos 
são uma maneira de restabelecer a harmonia à beira do caos" (FORD ${ }^{2}$, 1999 apud KABRAL, 2019: 110). Desta forma o senso de "não lugar" é colocado à prova e pessoas negras encontram possibilidade de viver, ainda que em um futuro utópico.

Assim, com o desenvolvimento dos estudos decoloniais e pós-coloniais, o afrofuturismo ganhou força nas produções artísticas, musicais e cinematográficas alcançando um público mais abrangente. Os filmes, acompanhados dos HQ's, Pantera Negra (2018), dirigido por Ryan Coogler, e Blade (1998), com direção de Stephen Norrington, deram visibilidade ao movimento. Em 2017 (SP), o coletivo MPIF (Mulheres Pretas Independentes da Favela) realizou o desfile de deusas africanas, com as irmãs Tasha e Tracie Okereke, que levantam para o debate a relação de pessoas negras com a indústria do embranquecimento. Há ainda o filme Bluesman, de Baco Exu do Blues, o álbum Afrofuturista (2016), de Ellen Oléria, as produções cinematográficas e musicais de Donald Glover, como a série Atlanta que expõe as experiências dos afro-diaspóricos, bem como o "currículo afrofuturista" de Will Smith que teve seu início com a série $U m$ Maluco no Pedaço, uma sitcom carregada de críticas sociais e raciais, e também os filmes Eu Sou a Lenda, Eu Robô e Mib: Homens de Preto, que definitivamente colocam o personagem negro como protagonista de um enredo futurista. Enfim, a lista é grande e todos aqui podem ser utilizados em sala de aula fornecendo uma educação antirracista. Passamos então aos

\footnotetext{
${ }^{2}$ FORD, Clyde W. Herói com Rosto Africano. São Paulo: Selo Negro, 1999.
} 
exemplos escolhidos: o curta Oya: A Ascensão do Orixá (2014) e os filmes Branco Sai, Preto Fica (2015) e Black is King (2020).

\section{Uma educação decolonial a partir da ficção Afrofuturista}

Ama Mazama parafraseia Mwalimu Shujaa quanto à afirmação de que a educação consiste na "transmissão à geração seguinte de valores e atitudes que reflitam a cultura de determinado grupo", no entanto afirma também que as práticas de aprendizagem direcionadas a crianças afro-diaspóricas nas escolas euro-norte-americanas evidenciam imagens negativas da população negra, resultando na absorção, pelo discente, destas figurações (MAZAMA, 2019). Da mesma maneira, dá-se no currículo educacional brasileiro que, ao valorizar o herói nacional e omitir a colaboração do negro na história, colabora para a construção ideológica racista (FERNANDES, 2005). Para superar esta situação é preciso revisar os currículos escolares, os quais são utilizados para definir esta população. No entanto, para compreender a colaboração da população negra é preciso muito mais que apenas inseri-las e transmiti-las em salas de aula, pois ela ainda está incorporada em quadros epistemológicos homogeneizantes que reforçam estereótipos. Para tanto, Catherine Walsh propõe uma interculturalidade crítica para a pedagogia decolonial.

Este processo deve privilegiar as experiências coloniais para aprendizagem que não se limitam aos muros da academia, em detrimento do que era organizado na pós-colonialidade que possuía o referencial europeu-ocidental como contraponto. Desta forma, a pedagogia decolonial 
colabora com os debates da interculturalidade, pois proporciona visões de mundo diferentes daquelas que colocam o homem branco como superior, compreende a permanência simbólica do silenciamento e contrapõe com estas no intuito de transformar as práticas e estruturas, contribuindo, por fim, para o desmonte de uma episteme ocidental homogeneizante (OLIVEIRA; CANDAU, 2010). No que diz respeito aos afro-diaspóricos, Fernando Jorge Pina Tavares afirma que:

Uma proposta educacional compatível com as realidades africanas, deve focalizar não só a identidade étnico-racial como também a diversidade cultural das nações africanas e suas diásporas. Isto é, deve ser uma proposta educacional democrática, que enfatize a igualdade racial na diferença cultural (TAVARES, 2015: 125).

Portanto, reconhecendo o caráter plurietnico da nação brasileira e frente tanto das reformas educacionais dos anos 1990 quanto das reivindicações do Movimento Negro no que diz respeito ao direito a educação, a conquista da Lei $n^{0} 10.639$ foi um importante marco no caminho para uma educação decolonial. A Lei de 9 de janeiro de 2003 “estabelece as diretrizes e bases da educação nacional, para incluir no currículo da rede de ensino a obrigatoriedade da temática 'História e Cultura Afro-Brasileira", e assim abarca:

O estudo da História da África e dos africanos, a luta dos negros no Brasil, a cultura negra brasileira e o negro na formação da sociedade nacional, resgatando a contribuição do 
povo negro nas áreas social, econômica e política pertinentes à História do Brasil (BRASIL, 2003: 1).

A partir destas afirmações proponho o uso do cinema afrocentrado. A possibilidade de utilizar o cinema como fonte histórica obteve oportunidade de ser debatida nos escritos de Marc Ferro em meados de 1960. Este historiador afirma que "o filme é uma fonte para entendermos os comportamentos, as visões de mundo, os valores, as ideologias de uma sociedade ou de um momento histórico" (FERRO3 ${ }^{3}, 1976$ apud SANTANA, 2008: 8). Todavia, diante de suas ambiguidades, como sua relação com a indústria cultural e o consumo sem reflexão, ainda possui capacidade de ressignificação ao passo que a ficção infiltra no imaginário desconstruindo e desmentindo mitos do sistema racializado (SANTOS, 2018). Assim, para potencializar o cinema como fonte é necessário desenvolver a sensibilidade junto ao aluno, expondo criticamente diferentes perspectivas para que ele próprio desenvolva uma forma própria de pensar. Denice Carvalho Santana relata que no Programa de Desenvolvimento Educacional utilizou um documentário sobre a questão da Palestina e observou que houve indignação por parte dos alunos com o que estava sendo retratado, concluindo uma experiência positiva, e que não devemos subestimar os alunos quanto a sua capacidade crítica (SANTANA, 2008).

\footnotetext{
${ }^{3}$ FERRO, Marc. Filme: uma contra-ánálise da sociedade? In: LE GOFF, J. \& NORA, Pierre (orgs). História: Novos Objetos. Rio de Janeiro: Francisco Alves, 1976.
} 
Santana afirma ainda que "[...] os melhores filmes [...] nos levam a pensar e questionar de que forma podemos contribuir para alguma transformação, alguma mudança, mesmo que pequena, em nós ou naqueles que nos rodeiam" (SANTANA, 2008: 8), passagem que dialoga muito com a proposta do presente trabalho. Pensar uma educação decolonial a partir de produções afrofuturistas permite uma melhor interpretação do lugar do afro-diaspórico no mundo e sobretudo na sociedade brasileira, em que seu passado deve ser compreendido para oferecer perspectiva para o futuro, mas também demonstrar para o resto da população a necessidade destas ações, ao passo que esta história, por tanto tempo escondida para debaixo do tapete, abre caminho para uma nova compreensão, somando todos os seus agentes e suas respectivas contribuições.

Antes de analisarmos os filmes escolhidos, cabe destacar que a escolha privilegiou produções que se adequassem as faixas etárias do Ensino Fundamental e Médio, visando a não exposição de conteúdos inadequados, como cenas de violência, preconceitos exacerbados e linguagens chulas. A escolha de uma produção nigeriana justifica-se por ser um filme próprio ao continente e, sendo referenciado cultural e religiosamente, oferece o ponto de partida para as análises, assim como África era o ponto de origem de afro-diaspóricos. Partindo para o outro lado do Atlântico, chegamos à indústria norte-americana e deparamo-nos com centenas de filmes de fácil acesso.

Beyoncé é um grande símbolo na luta antirracista dos Estados Unidos, tema que perpassa suas produções já há algum tempo, mas aqui a 
cantora opta por ir contra estereótipos racistas e sexistas impostos à pessoa negra, tratando de temas sensíveis de forma empática e dando visibilidade a diversidade religiosa de matrizes africanas.

Por fim, no intuito de localizar a análise em um contexto mais próximo ao nosso, o último filme, de produção brasileira, pretende compreender a situação complexa do afro-diaspórico que encontra-se historicamente subjugado, sobretudo quando se trata de abordagens policiais, algo recorrente em nosso país e que merece maior destaque. $\mathrm{O}$ diálogo entre passado e presente pode abrir espaço para esse tipo de debate em sala de aula, destacando as problemáticas de políticas raciais levadas a cabo pelo Estado.

$\mathrm{E}$ eis que, finalmente, chegamos às análises. O curta Oyá: $A$ Ascensão do Orixá, lançado em 2014, , foi dirigido por Nosa Igbinedion e possui em torno de 12 minutos. A história gira em torno de Adesuwa (Ethosheia Hylton), uma jovem devota aos orixás e uma das poucas pessoas que ainda possui forte ligação com as divindades, em especial com a deusa dos raios e tempestades Oyá (também chamada de Iansã) com quem estabelece um laço transcendental. Por esta razão fica sob sua responsabilidade encontrar a "chave", que liga o mundo espiritual ao físico, e protegê-la para que não caia nas mãos de outros orixás antigos que desejam a extinção dos humanos. Espécie esta que já se encontra a beira da iminente autodestruição.

\footnotetext{
${ }^{4}$ Disponível em: OYA: RISE OF THE ORISHA FULL SHORT MOVIE - (2015) African superhero movie - YouTube. Acesso em: $21 \mathrm{fev} 2021$.
} 
Nos primeiros minutos do curta, vemos uma cena sendo utilizada em favor da representação religiosa e cultural, na qual há um altar com pequenas esculturas de cabeças, que lembram aquelas produzidas em terracota pelos povos iorubá. Babatunde Lawal afirma que a arte tradicional africana, para além da apreciação, configura um "meio para um fim" pois possui um fim utilitário e, sobretudo, prestígio religioso. Os altares, da mesma maneira, constituem a "face do espírito" sendo que o que possui face é acessível (LAWAL, 1983). Assim, no momento de suas preces à deusa Oyá, em frente ao altar Adesuwa, faz uso destes objetos para aperfeiçoar sua forte ligação com as divindades e concluir aquilo que the foi designado.

O curta também oferece algo emergente em nossa sociedade, sendo necessário para que possamos superar o negacionismo difundido em relação ao racismo que atravessa as vivências de afro-diaspóricos: representatividade negra. Entendo representatividade a partir do conceito desenvolvido por Clyde Ford, "herói de rosto africano", expressão que oferece uma via ao afro-diaspórico para que supere as duas questões importantes afirmadas por Ford e reforçadas por Fábio Kabral: as aflições cotidianas, seja na forma do racismo cultural, discriminatório e, sobretudo institucional; e a alegação da vitimização, que estas pessoas recebem como respostas após as contestações. Kabral continua afirmando que:

O herói de rosto africano, num mundo pós-colonial, representa a heroína e herói descendentes de rainhas e reis divinos, que sobreviveram aos horrores da travessia e da escravidão, e hoje lutam para se impor no mundo, para orgulhar a si e aos 
ancestrais. Na perspectiva afrofuturista, a importância [...] é reconhecer e despertar os heróis ancestrais que existem dentro de nós, e, dessa forma, dar um novo passo para construir um novo futuro (KABRAL, 2019: 113).

A partir disto, a presença das divindades no curta possibilita explorar a religiosidade dos orixás e suas complexidades tendo em vista seu caráter polissêmico. A apresentação de Oyá, Ogun e Xangô oferece uma interpretação melhor localizada das entidades e ainda combate a demonização das religiões africanas. Através da exposição destas entidades, os "heróis de rosto africano" oferecem um espelho a crianças negras que necessitam de perspectiva de futuro.

Pode-se observar alguns aspectos centrais no curta passíveis de serem utilizados em sala de aula, como o desenvolvimento de práticas e saberes, tanto em África como no diálogo entre o continente e o Brasil (religiões, símbolos e a própria capoeira). Por exemplo, o sincretismo religioso que as crenças africanas sofreram ao chegar na América Portuguesa que, mescladas a religião católica, fez alguns orixás serem interpretados como santos e santas, e a forte presença da mitologia no cotidiano desta sociedade. Apoiando-se na Base Nacional Comum Curricular, percebemos que é possível, a partir desta obra, favorecer o debate entre os discentes quanto a questões relacionadas "às diferentes formas de organização política na África” (BNCC: 420), observando os mitos fundadores relativos à sociedade iorubá, possibilitando também “identificar aspectos e processos específicos [...] antes da chegada dos 
europeus [...]" (ibid: 423) para contrapor com outras sociedades antigas. Observando questões relacionadas ao meio africano faz sentido pensar na "formação das culturas e dos povos, relacionando-os com o espaço geográfico ocupado" para "analisar o papel das culturas e das religiões na composição identitária dos povos antigos" (ibid: 415).

Mediante a possibilidade de interdisciplinaridade com aulas de Ensino Religioso, destacamos também que é possível, a partir da obra, oferecer ao aluno outras "ideias de divindades de diferentes manifestações e tradições religiosas", "mitos de criação" e as "funções e mensagens religiosas" contidas nestes (ibid: 449, 451). Junto a este aspecto é importante também mostrar "representações religiosas em diferentes expressões artísticas [...] reconhecendo-as como parte da identidade de diferentes culturas e tradições religiosas" (ibid: 449). Aqui acho interessante contrapor com a demonização destas religiões e o aspecto de "artes tribais", ambos processo desenvolvidos durante o Imperialismo.

Em última análise, as produções afro-centradas também chegam para ocupar seu lugar na ficção científica e apresentar novos mundos e experiências frente ao mainstream, que permanece perpetuando os mesmos enredos. Explorar Grécia, Roma, Idade Média e suas transformações apresentando novas interpretações com livros, filmes ou jogos continua sendo algo frutífero e mesmo educativo em certa medida, mas apresentar novos mundos que não o eurocentrado oferece uma abundância de possibilidades de novas histórias, sobretudo do continente africano que possui uma variedade cultural enorme. Novos mundos e perspectivas 
podem ser apresentados, colocando ainda o destaque da população negra no enredo. Ademais, cabe dizer que o curta Oya: A Ascensão do Orixá é bem vindo neste momento pois possui um apelo comercial de um filme de super-herói, tema bem explorado com adaptações de livros, jogos e HQ's.

O álbum visual afrofuturista, Black is King, dirigido por Beyoncé Knowles e lançado em 2020, acompanha o enredo da animação popularmente conhecida, O Rei Leão (1994), o que pode colaborar para melhor compreensão do filme pelo aluno. É importante ressaltar que ainda que o filme seja uma releitura da live action de $O$ Rei Leão, lançado em 2019, a jornada de Simba, bem como o reino de Mufasa nas savanas africanas, são representados por pessoas negras, desestabilizando as "metáforas de desumanização", como denomina José Pereira, onde o primeiro símbolo consiste na animalização de pessoas negras, que nos filmes são representadas por animais falantes (CUSTÓDIO; OLIVEIRA; VALLE, 2020). A cantora volta-se para matrizes africanas ao demonstrar aspectos culturais dos povos de etnia zulu, xhosa, mursi, bantu, dogon e tantos outros para "que preto seja sinônimo de glória" mostrando que "sua história é seu futuro" e que há sempre um caminho para casa, assim como Simba procura o seu: ele, assim como afro-diaspóricos, perpassa por povos e culturas para conhecer e lembrar-se de seu "reino". O filme também exalta a ancestralidade com a presença dos orixás iorubá como Obá, Oxum, Ogum e Oxóssi, potencializa as experiências das sociedades matrilineares, não raras nos corpos sociais africanos, apresentando um novo e diferente referencial cultural para afro-diaspóricos, expondo ainda as "várias 
Áfricas" diferentes da imagem caricata daquele continente subalterno, dominado e majoritariamente florestal. Além disso, em suas músicas, a artista também referencia figuras importantes na história de africanos e afro-diaspóricos como Mansa Musa, a Rainha de Sabá, Nina Simone e Michael Jackson. O docente poderá escolher dentre essa variedade para trabalhar, mas, diante do tamanho do filme, destaco algumas questões que condizem com o movimento afrofuturista.

Beyoncé apresenta a música Find Your Way Back e demonstra um mito em que pessoas descendem das estrelas, apontando um possível "local" de ancestralidade. Todavia, durante a música repete a frase "Encontre seu caminho de volta/ Não deixe esta vida te enlouquecer" ${ }^{5}$ e compreendo que, assim como em Sun Ra, Beyoncé faz uma analogia em relação à viagem pelo Atlântico: esta "passagem do meio" ocasionou a quebra de autoestima dos futuros escravizados e destruiu suas identidades étnicas. No entanto, ainda que seja necessário que pessoas negras encontrem seu lar novamente, é quase impossível que o afro-diaspórico mapeie seus ancestrais com precisão. Portanto, podemos assimilar o "lugar" a um "mito", pois, parafraseando novamente Clyde Ford, com o auxílio do mito podemos enfrentar um trauma e "[...] restabelecer a harmonia à beira do caos" (FORD", 1999 apud KABRAL, 2019: 110). Sendo então a mitologia africana um ponto referencial de ancestralidade, o afro-diaspórico adquire pertencimento e pode impedir que a vida the enlouqueça, visto que

\footnotetext{
5 "Find your way back/ Don't let this life drive you crazy" ${ }^{6}$ FORD, op. cit.
} 
encontra-se em um meio que constantemente desfavorece a sua existência, com silenciamento e embranquecimento.

Outra questão a ser tratada, diz respeito ao corpo negro. A partir da maior circulação de corpos negros e estrangeiros, tidos como mercadorias nas metrópoles durante o período colonial, a vontade classificatória foi elevada, o que demandou formas específicas de controle político. Jonatas Ferreira e Cynthia Hamlin afrmam que corpos de homens e mulheres negras apresentam características e estereótipos ambivalentes: o homem negro é passível de dominação e selvagem, mas também é luxurioso, vicioso; a mulher negra é associada à fertilidade e, concomitantemente, sexualizada, como o caminho da perdição (FERREIRA; HAMLIN, 2010). Esses discursos do outro denotam a necessidade de civilização, bem como a sua impossibilidade, e a partir desta civilização há o controle. Diante deste contexto, o corpo negro não foi visto como digno de beleza e, em um certo momento do filme, Beyoncé afirma que "nossos irmãos e irmãs andam por aí com coroas em seus bolsos devido a um clima de repressão”.

Para que este corpo, antes tido como monstruosidade, seja um signo de elegância, ele precisa ser definido a quem o pertence. Em Already temos a seguinte frase é: "Seja seu próprio rei/ Não deixe ninguém governar seu mundo"7 enquanto homens negros dançam juntos, com ternos ou as vezes sem. O interessante é perceber como o filme proporciona beleza ao corpo negro sem sexualizá-lo. Na música Brown Skin Girl as mulheres negras são enaltecidas, demonstrando como o colorismo impacta também no debate

\footnotetext{
7 "Be your own king/ Make nobody come rule your world"
} 
sobre padrão de beleza e que, mesmo não sendo a pele branca, ainda impõe-se o tom mais claro possível a estas mulheres para que possam ser “aceitas" socialmente. A diversidade dos tons de pele é demonstrada com artistas como Lupita Nyong’o, Kelly Rowland e Naomi Campbell. Também mostra mulheres em seus núcleos familiares cotidianos, tão mais distantes de um padrão, bem como jovens em um baile debutante, no qual todas são dignas do reconhecimentos da própria beleza, sem serem padronizadas ou sexualizadas.

Por fim, o filme compreende as atitudes de pessoas negras diante de seu próprio contexto e tenta oferecer símbolos para que contribua com o "caminho de volta" ao desmistificar estereótipos. Os alunos veem-se representados e podem analisar as "situações cotidianas que remetam à percepção de mudança, pertencimento e memória" (BNCC: 409). Esta representatividade também traz debates pertinentes ao contexto atual e abre espaço para discutir as "relações causais entre as ideologias raciais e o determinismo no contexto do imperialismo europeu e seus impactos [...]”, "identificando permanências na forma de preconceitos, estereótipos [...]" (BNCC: 425, 427) designados às populações negras mediante as formas diversas de violência, para além de físicas, sofridas desde os anos de escravidão até hoje. Exemplos como o colorismo, a sexualização e animalização do corpo negro, padronizado para ser "aceito", devem ser debatidos com sensibilidade e empatia.

Voltando-se agora para um contexto mais nacional, no período da formação da República brasileira, afro-diaspóricos foram rebaixados a 
quase nada, pois mesmo após a abolição em 1888 nenhuma pessoa negra recebeu qualquer tipo de auxílio do governo para estruturar-se na vida ou mesmo adentrar com dignidade no mercado de trabalho. E, ainda que seu esforço braçal fosse continuamente utilizado para a organização da nação, René Marc da Costa Silva afirma que os projetos imigrantistas pautavam-se na construção de uma sociedade economicamente próspera, baseando-se em um "nacionalismo étnico", na qual, pelas mãos capacitadas dos não-negros, o capitalismo seria melhor implantado e encaminhado (SILVA, 2013). Portanto, a crítica quanto ao processo de construção e naturalização do racismo, um racismo institucional marcado por determinismos econômicos que limitam a condição da pessoa negra brasileira, é exposta no filme Branco Sai, Preto Fica, dirigido por Adirley Queirós.

A produção torna-se uma fonte produtiva para discutir o racial profiling no contexto brasileiro. Compreendido como a "filtragem racial", o termo diz respeito às "práticas racialmente tendenciosas de identificação de suspeitos", em que as representações sociais estereotipadas, como classe social, localização territorial e identidades raciais, são os principais fatores que justificam abordagens policiais e que, no fim, definem relações de poder desiguais (ANUNCIAÇÃO; TRAD; FERREIRA, 2020). O título faz referência à abordagem policial em um baile funk na década de $1980 \mathrm{em}$ Ceilândia, Brasília, e demonstra na forma de um documentário as consequências daquela noite, tornando as denúncias uma memória coletiva. A frase "branco sai, preto fica" sintetiza bem o racial profiling em que, a partir de características fenotípicas, a abordagem policial muda a vida de 
pessoas que, de alguma forma, procuravam lazer à sua maneira e, como as relações de poder modificam-se mediante o sujeito, todas as pessoas brancas retiram-se sem sofrer retaliação.

Durante o filme também deparamo-nos com a segregação racial a partir da dualidade entre centro e periferia. O personagem Marquim teve de usar cadeira de rodas após a noite do baile e, em determinado momento, tenta conseguir passaportes para "entrar" em Brasília, tido como um lugar elitizado. Da mesma maneira como a periferia ainda hoje é retratada como um satélite das regiões centrais, um local de despejo. De qualquer forma, a periferia ainda possui uma identidade, o funk e o rap são utilizados como denúncia social, mas Marquim e, posteriormente, Sartana, personagem que precisou amputar uma perna devido a noite da abordagem policial, planejam fugir deste meio estigmatizado que vivem, destruindo aquilo que continua lhes impondo uma vida difícil. Cabe destacar que ambos os personagens, e podemos imaginar que igualmente outras pessoas, não foram auxiliados por políticas públicas, pois, como afirmam Diana Anunciação, Leny Alves Bonfim Trad e Tiago Ferreira, um dos principais mecanismos do racismo institucional consiste na omissão legal que acaba por viabilizar "distorções sociorraciais e territoriais" (ibid: 4).

A questão afrofuturista mais aparente reside no personagem Dimas Cavalanças, que vem de 2070 para impedir uma catástrofe em Brasília e juntar provas para processar o Estado pelo trato com pessoas negras, provas que apenas Sartana parece possuir. Ao analisar mais profundamente, podemos citar que o que imaginamos ao pensar em futurismo pode estar 
bem próximo do que vemos na série de animação Os Jetsons, anteriormente comentada. No entanto, a máquina de Cavalanças é um container e Sartana precisa hackear o sistema de uma perna de melhor qualidade para seu próprio benefício (peças reutilizadas): em ambos os casos, demonstram como ferramentas do cotidiano, e nitidamente provenientes de um contexto mais periférico, podem ser utilizadas para novas tecnologias, bem como pode mesmo nos aproximar mais de uma ficção científica. Entretanto, uma outra interpretação sobre a relação entre os homens negros e as máquinas com as quais se relacionam podem servir como demarcação de poder, visto que estas limitam seus movimentos e constantemente precisam de reparos, como a máquina do tempo de Cavalanças, o elevador de Marquim e a perna de Sartana. Em todo caso, por esta viagem no tempo, o filme apresenta de forma quase educativa a compreensão do passado para mudar o futuro, pois este ainda está caótico e segregado.

Em última análise, no filme os personagens negros participam ativamente da trama viajando pelo túnel do tempo e orquestrando planos para destruir a elite política que perpetua o racismo em suas vidas, atitudes que podem ser espelhadas em outros momentos da história desta população que nem sempre permaneceu em silêncio frente a sua subalternização. Compreendo que, desta forma, é possível explorar as lutas raciais que ainda hoje são enfrentadas, tendo em vista a verossimilhança com a realidade do ocorrido na noite do baile e dessa forma conscientizar e problematizar junto aos discentes "as causas da violência contra populações marginalizadas" (BRASIL, 2018: 427). É possível também “identificar e relacionar aspectos 
das estruturas sociais da atualidade com os legados da escravidão no Brasil e discutir a importância de ações afirmativas" (ibid.: 423), visto que nossos personagens carecem de políticas públicas. Em relação a formação das periferias brasileiras, seria interessante discutir a "inserção dos negros na sociedade brasileira pós-abolição [...]" e a "importância da participação da população negra na formação econômica, política e social do Brasil” (ibid.: 425) para compreender a formação destes locais satélites, frente aos centros, e as implicações destes locais na vida destas pessoas.

\section{Conclusão}

Após séculos de violência imperialista e ressignificação por terceiros para caber em uma lógica ocidental de progresso e modernidade, populações não-européias, aqui em específico africanos e afro-diaspóricos, foram identificados como povos atrasados, seguindo uma lógica colonial que precisava justificar a busca por novas fontes de riquezas. Toda esta "biblioteca colonial", como afirma Valentin Mudimbe, serviu de identidade forjada destes povos em prol de um Ocidente antagônico. Como consequência, o tráfico escravista espalhou por quase todo o globo afro-diaspóricos que agora tem dificuldade de se conectar a suas origens. Para tanto, a filosofia e cultura afrocentrada são importantes na construção da identidade do sujeito afro-diaspórico que estava submetido a definições cristalizantes e racializadas.

A corrente Pan-africanista, porém, pode correr o risco anacrônico de criar um passado africano exuberante e cair em um essencialismo exótico, 
intensificando-se mediante o contexto das lutas pelas independências e formação dos nacionalismos africanos em que uma "unidade cultural africana" poderia ser útil às complexidades políticas do período pós-colonial. Entretanto, estudos posteriores caminham ao lado da forte crítica teórica, ao passo que uma unidade africana articula-se para tornar-se uma unidade étnica como haussa, iorubá ou mandinga. Paul Gilroy afirma ser necessário questionar as identidades coletivas, sobretudo quando são pautadas em parâmetros raciais. Também, o historiador Achille Mbembe afirma que o movimento pan-africano articula o marxismo visando a emancipação e considera o colonialismo, a escravidão e o apartheid momentos chaves para compreender os processos históricos da África na contemporaneidade. No entanto, para ele é necessário problematizar estes momentos, bem como a colaboração do próprio africano, para que a “vitimização" seja superada. Ou ainda Marc-Louis Ropivia e a ideia de diversidade cultural africana sob uma organização federalista (SANTOS, 2019).

Assim, mediante ao amplo, porém igualmente fértil, quadro cultural é possível construir um imaginário de que a pessoa negra existirá no futuro e corretamente inserida em um meio que perpetue sua existência e cultura. Assim a afrocentricidade favorece estudos decoloniais que não partem do século da Ilustração e abrem caminho para outras filosofias e visões de mundo. Esta noção não-eurocêntrica pode expandir-se para além da academia com um discurso mais direto do que simplista e alcançar as discussões nos ensinos fundamental e médio. 
O uso de produções afrofuturistas, a representatividade que protagonistas negros oferecem ao exporem suas histórias e experiências, $\mathrm{o}$ autoconhecimento e a construção de uma identidades, com bases culturais referenciadas, e o sentimento de pertencimento também entram em combate com as imagens negativas de África disseminadas em filmes, séries, notícias internacionais e nacionais, bem como viabiliza um debate acerca do trauma coletivo, abrindo caminho para uma possível superação de questões delicadas. O "herói de rosto africano", de Clyde Ford, em alguns casos pode apresentar um caráter comercial, mas não se distancia da intenção de representar o negro apto na construção de seu próprio futuro.

Observando os filmes escolhidos para o presente trabalho, Black is King remete a um passado cultural da África que por tanto tempo lhe foi negado, apresentando que, por trás da escravidão, os afro-diaspóricos saíram de um lugar que pode ser referenciado com orgulho. Temos também Oya: A Ascensão do Orixá, que apresenta um caráter um tanto comercial, mas oferece um "herói de rosto africano" para a pessoa negra, algo que só foi apresentado até o momento com o grande alcance do filme Pantera Negra. Sendo assim, uma produção africana, de Nollywood, oferece visibilidade para africanos criarem mundos utópicos em que são aliados ou inimigos de suas próprias histórias, denotando a complexidade que os cerca.

Branco Sai, Preto Fica apresenta um contexto mais próximo ao nosso e expõe as consequências de uma ideologia racializada aliada ao mercado capitalista e as políticas de segurança do Estado, baseadas em 
estereótipos caricatos, que menosprezam e ao mesmo tempo marginalizam pessoas negras, mas estas são as principais no enredo e levam a história para seu trágico (ou não) fim.

Por fim, basta dizer que mesmo a Lei 10.639/2003 possibilitando a exposição da história e cultura afro-brasileira, ainda há muito a ser feito para superar as dificuldades escolares - que não serão abordadas aqui. Sendo assim, aproveitar-se da cultura pop para o ensino decolonial, que originalmente não abarcava tais questões, favorece aqueles que precisam ter um referencial de si mesmos e sua interpretação quanto a temas relacionados à África, Brasil e o que se desenvolveu neste meio.

\section{Referências}

ALBUQUERQUE, Afonso de.; CORTEZ, Krystal. Cultura pop e política na nova ordem global: lições do Extremo-Oriente. In: SÁ, Simone Pereira; CARREIRO, Rodrigo; FERRARAZ, Rogerio. Cultura Pop. Salvador: Edufba, 2015.

Disponível em: https://www.academia.edu/25511663/Cultura_pop_e_pol\%C3\%ADtica_na _nova_ordem_global_li\%C3\%A7\%C3\%B5es_do_Extremo_Oriente. Acesso em: 8 fev. 2021 .

ANUNCIAÇÃO, Diana; TRAD, Leny Alves Bonfim; FERREIRA, Tiago. "Mão na cabeça!": abordagem policial, racismo e violência estrutural entre jovens negros de três capitais do Nordeste. Saúde e Sociedade, v. 29, n. 1, p. $1-13,2020.2$ Disponível em: https://www.scielosp.org/article/sausoc/2020.v29n1/e190271/\#. Acesso em: 08 jul 2021.

BARBOSA, Muryatan Santana. Pan-africanismo e teoria social: uma herança crítica. África, n. 31-32, p. 135-155, 2012. Disponível em: 
https://www.revistas.usp.br/africa/article/view/115352. Acesso em: 04 jul 2021.

BRASIL. Ministério da Educação. Base Nacional Comum Curricular. Brasília, 2018.

BRASIL. Lei $n^{\circ}$ 10.639, de 9 de janeiro de 2003. Altera a Lei $n^{\circ} 9.394$, de 20 de dezembro de 1996, que estabelece as diretrizes e bases da educação nacional, para incluir no currículo oficial da rede de ensino a obrigatoriedade da temática "História e Cultura Afro-Brasileira", e dá outras providências. Diário Oficial da União. Brasília, DF, 10 jan. 2003. Disponível em: https://legislacao.presidencia.gov.br/atos/?tipo=LEI\&numero=10639\&ano= 2003\&ato=431MTTq10dRpWTbf4. Acesso em: 25 jun 2021.

CUSTODIO, Denizard; OLIVEIRA, Laura; VALLE, Francisco. Quando eu for humano: A Desumanização Do Negro Nas Animações. In: 43 Congresso Brasileiro de Ciências da Comunicação, 2020, Salvador, Bahia. ANAIS PROVISÓRIOS DO INTERCOM 2020, 2020. Disponível em: http://www.intercom.org.br/sis/eventos/2020/resumos/R15-0492-1.pdf. Acesso em: 04 jul 2021.

DIOP, Cheikh Anta. The African Origin of Civilization: myth or reality. Chicago: Lawrence Hill \& C.O., 1974.

FERNANDES, José Ricardo Oriá. Ensino de História e diversidade cultural: desafios e possibilidades. Cadernos Cedes, Campinas, vol. 25, n. 67, set./dez. 2005, p. 378-388. Disponível em: Uma publicação Publicações - CEDES (unicamp.br). Acesso em: 19 fev 2021.

FERREIRA. Jonatas; HAMLIN. Cyntia. Mulheres, negros e outros monstros: um ensaio sobre corpos não civilizados. Revista Estudos Feministas, v. 18, n. 3, p. 811-836, 2010. Disponível em: https://www.scielo.br/j/ref/a/pNrk63zWDDbTCVtrrg5TryH/?lang=pt\&for mat $=$ html\#ModalArticles. Acesso em: 08 jul 2021. 
FINCH, C.; NASCIMENTO, E.; Abordagem afrocentrada, história e evolução. In: NASCIMENTO, E. (org.). Afrocentricidade: Uma abordagem epistemológica inovadora. São Paulo, Selo Negro 2009, pp. 37-69.

KABRAL, Fábio. Afrofuturismo: ensaio sobre narrativas, definições, mitologia e heroísmo. In: LIMA, Emanuel Fonseca; SANTOS, Fernanda Fernandes dos; NAKASHIMA, Henry Albert Yukio, TEDESCHI, Losandro Antonio (org.). Ensaios Sobre Racismos: Pensamento de Fronteira. São Paulo, Balão Editorial, 2019, pp. 104-115. Disponível em: https://ocarete.org.br/acervo/ensaios-sobre-racismos/. Acesso em 17 fev. 2021.

LAWAL, Babatunde. A arte pela vida: a vida pela arte. Afro-Ásia, n. 14, 1983.

Disponível em: https://periodicos.ufba.br/index.php/afroasia/article/view/20820/13421. Acesso em: 07 jan. 2021.

MAZAMA, A. Afrocentricidade como um novo paradigma. In: NASCIMENTO, E. (org.). Afrocentricidade: Uma abordagem epistemológica inovadora. São Paulo: Selo Negro, 2009, pp. 111-127.

OLIVEIRA, Luiz Fernandes de; CANDAU, Vera Maria Ferrão. Pedagogia decolonial e educação antirracista e intercultural no Brasil. Educação em Revista, v. 26, n. 1, p. 15-40, 2010. Disponível em: https://www.scielo.br/j/edur/a/TXxbbM6FwLJyh9G9tqvQp4v/?lang=pt\#. Acesso em: 05 jul. 2021.

RANGEL, Edson. Afrofuturismo e questões políticas do negro na ficção científica. Revista do Audiovisual Sala 206, Vitória, n. 5, p. 129-148, jan./jul. 2016. Disponível em: https://periodicos.ufes.br/sala206/article/view/13798. Acesso em: 17 fev. 2021.

SANTANA, Denice Carvalho. O cinema nas aulas de História. Projeto O Cinema nas Aulas de História, Programa de Desenvolvimento Educacional 
(PDE), 2008. Disponível em: https://gtenshist.webnode.com.br/pde/. Acesso em: 08 jul. 2021.

SANTOS, Harlan Gelson Rodrigues dos. O pensamento pan-africano na contemporaneidade: o caso da Agenda 2063. 2019. Trabalho de Conclusão de Curso (Licenciatura em História) - Universidade de Brasília, Brasília, 2019.

SANTOS, Wellington Oliveira dos. Identidade negra, relações étnico-raciais na diáspora e o filme Pantera Negra: para uma discussão educacional. Revista de Estudos Universitários - REU, v. 44, n. 1, ago. 2018.

http://periodicos.uniso.br/ojs/index.php/reu/article/view/3275. Acesso em: 17 fev 2021.

SILVA, René Marc da Costa. A Constituição de 1988 e a discriminação racial e de gênero no mercado de trabalho no Brasil Brasileiro. Int. Law: Rev. Colomb. Derecho Int., Bogotá, n. 23, p. 235-266, Dec. 2013. Disponível em: http://www.scielo.org.co/scielo.php?script=sci_arttext\&pid=S1692-815620 13000200008\&lng=en\&nrm=iso. Acesso em: 4 jul 2021.

SOUZA, Esdras Oliveira; ASSIS, Kleyson Rosário. O Afrofuturismo como dispositivo na construção de uma proposta educativa antirracista. Entheoria: Cadernos de Letras e Humanas, Serra Talhada, v. 6, n. 1, jan./dez. 2019, p. 64-84. Disponível em: http://journals.ufrpe.br/index.php/entheoria/article/view/3009. Acesso em: 17 fev. 2021.

TAVARES, Fernando Jorge Pina. Pan-africanismo e educação das relações étnico-raciais - Contributo para a constituição de uma filosofia da educação sul-sul. Revista Itinerários da filosofia da educação, Porto, n. 13, 2015. Disponível em: http://aleph20.1etras.up.pt/index.php/itinerariosfe/article/view/690. Acesso em: 05 jul. 2021. 
Cadernos de Clio, Curitiba, v. 11, $\mathrm{n}^{\circ} .2,2020$

Recebido em: 04/03/2021 Aceito em: 09/07/2021 